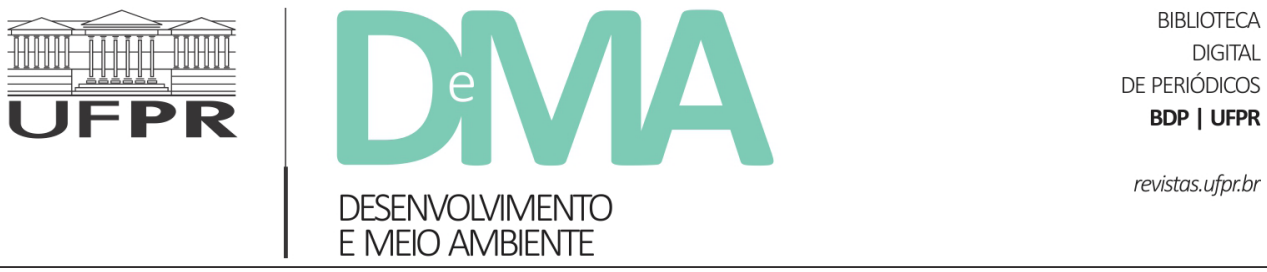

\title{
Repoblamiento ganadero con una raza local ante un desastre natural: análisis de una política interinstitucional y participativa en la Patagonia Argentina
}

\author{
Repovoamento pecuário com uma raça local diante de um desastre \\ natural: análise de uma política interinstitucional e participativa na \\ Patagônia Argentina
}

\section{Livestock restocking with a local breed in the face of a natural disaster: analysis of an interinstitutional and participatory policy in Argentinean Patagonia}

\footnotetext{
Sofía LAMMEL ${ }^{1 *}$, Mercedes EJARQUE ${ }^{1}$, Pablo LOSARDO², Marcelo Pérez CENTENO ${ }^{1}$, María Rosa LANARI ${ }^{3}$

${ }^{1}$ Área de Investigación para la Agricultura Familiar Región Patagonia, Instituto Nacional de Tecnología Agropecuaria, Neuquén, Argentina.

${ }^{2}$ Secretaría de Agricultura Familiar, Campesina e Indígena, Ministerio de Agricultura, Ganadería y Pesca, Río Negro, Argentina.

${ }^{3}$ Estación Experimental Bariloche, Instituto Nacional de Tecnología Agropecuaria, Río Negro, Argentina.

*E-mail de contato: lammel.sofia@inta.gob.ar
}

Artículo recibido el 10 de septiembre, 2019, versión final aceptada el 28 de agosto, 2020, publicado el 6 de mayo de 2021.

RESUMEN: En un contexto de desastre natural ocasionado por la erupción del Complejo volcánico Fisural Cordón Caulle- Puyehue, este artículo analiza el proceso de desarrollo de la iniciativa de Repoblamiento con Cabras Criollas Neuquinas implementada en la provincia de Río Negro, en la Patagonia Argentina. A partir del enfoque del ciclo de las políticas públicas, la investigación evidencia en el diseño, la implementación y la evaluación, un desarrollo centrado en la participación social y la articulación interinstitucional. Incluyó las organizaciones de productores, el apoyo de gobiernos locales y acciones a corto y largo plazo (financiamiento, selección de participantes y logística). Los resultados de la evaluación del repoblamiento ganadero con razas locales muestran que los animales reintroducidos se adaptaron a las condiciones socioproductivas del área, aportaron a la seguridad alimentaria y a garantizar el modo de vida de los productores ganaderos. Esta política pública ha mostrado capacidad de resiliencia frente a las emergencias, aprovechando y tejiendo vínculos sociales a partir de saberes y recursos locales.

Palabras clave: repoblamiento ganadero; articulación interinstitucional; seguridad alimentaria; políticas públicas.

Desenvolv. e Meio Ambiente usa uma Licença Creative Commons - Atribuição-NãoComercial-SemDerivações 4.0 Internacional 
RESUMO:

Em um contexto de desastre natural causado pela erupção do Complexo Vulcânico Fisural Cordon CaullePuyehue, este artigo analisa o processo de desenvolvimento da iniciativa de repovoamento com Cabras Crioulas do Neuquén implantada na província de Río Negro, na Patagônia Argentina. A partir da abordagem do ciclo de políticas públicas, a pesquisa mostra na concepção, implementação e avaliação, um desenvolvimento voltado para a participação social e articulação interinstitucional. Incluindo organizações de produtores, apoio do governo local e ações de curto prazo (financiamento, seleção de participantes e logística). Os resultados da avaliação do repovoamento bovino com raças locais mostram que os animais reintroduzidos se adaptaram às condições sócio-produtivas da área, contribuindo para a segurança alimentar e garantindo o modo de vida dos pecuaristas. Esta política pública ha demostrado resiliencia ante las emergencias, aproveitando e tecendo vínculos sociais baseados em conhecimentos e recursos locais.

Palavras-chave: repovoamento pecuário; articulação interinstitucional; segurança alimentar; políticas públicas.

ABSTRACT: In a context of natural disaster caused by the eruption of the Puyehue-Cordon Caulle Volcanic Complex, this article analyzes the development process of the restocking initiative with Cabras Criollas Neuquinas (Neuquén Criollo Goats) implemented in the province of Río Negro, in Argentinean Patagonia. From the approach of the cycle of public policies, this research shows in the design, implementation and evaluation, a development focused on social participation and inter-institutional articulation. It has involved producer's associations, support from local governments and short- and long-term actions (financing, participants selection and logistics). The results of the evaluation of the restocking of livestock with local breeds shows that the reintroduced animals adapted to the socio-productive conditions of the area, contributed to food security and to guarantee the way of life of the livestock producers. This public policy has shown resilience towards emergencies, taking advantages of and weaving social relations based on local knowledge and resources.

Keywords: livestock restocking; inter-institutional articulation; food security; public policy.

\section{Introducción}

En las últimas décadas, los problemas ambientales de envergadura global, sostenidos en el tiempo o con impactos sociales profundos, han motivado las reflexiones y el análisis con enfoques interdisciplinarios, que consideran las influencias y condicionamientos mutuos entre la sociedad y la naturaleza (Descola \& Pálsson, 2001). En América Latina este debate ha resultado particularmente central por el riesgo que la exportación de bienes derivados de la naturaleza en las economías nacionales genera en la soberanía alimentaria (Giarracca \& Teubal, 2013); y los constantes desafíos que estos problemas y la alternancia de ciclos económicos positivos y negativos generan en la política pública (Sinnott et al., 2010; Göbel et al., 2014). Por ello, resulta clave comprender los modos en que el Estado puede participar en la promoción y garantía de los derechos de seguridad y soberanía alimentaria (De Gorban et al., 2011), considerando que la interacción entre los saberes locales y el conocimiento científico puede contribuir a la solución de problemas ambientales (Floriani \& Vergara, 2015; Argueta Villamar \& Perez Ruiz, 2019).

Históricamente, en Argentina, y especialmente en la región sur de la Patagonia, los procesos de valorización y utilización de la naturaleza fueron centrales para la apropiación del espacio (Galafassi, 2010; Schweitzer, 2014). Desde fines del siglo XIX las zonas de tierras secas fueron destinadas al desarrollo de un modelo de producción basado en 
la ganadería ovina extensiva y la exportación de lanas. Dicho modelo ha sido fomentado desde el Estado e implicó un uso intensivo de la naturaleza, principalmente de los forrajes, con la consecuente presión y degradación de la tierra (Andrade, 2005; Galafassi, 2010). En los últimos 30 años, este modelo ha sido difícil de sostener, entre otros factores, por el deterioro ambiental producto de la desertificación de los suelos; un ciclo de sequía que abarcó gran parte del inicio del siglo XXI (Galafassi, 2010; Ejarque, 2015). Esta situación se agravó el 4 de junio de 2011 con la erupción del complejo volcánico fisural Cordón Puyehue-Cordón Caulle, ubicado en el país vecino de Chile. El depósito de cenizas volcánicas ocasionado por dicha erupción fue considerado un desastre natural, al originarse por causas naturales pero con daños en la sociedad y en sus medios de vida. Los pequeños productores ganaderos fueron especialmente afectados, ya que dada su situación de vulnerabilidad (Blaikie et al., 1994) vieron reducida su capacidad para resistir y recuperarse de sus efectos.

Una de las regiones más afectadas por la erupción de 2011 fue la Línea Sur de la provincia de Río Negro. En la actividad ganadera se registraron impactos socioeconómicos severos, relacionados a la reducción del stock ganadero, el deterioro de los ingresos prediales y extraprediales y el éxodo rural (Muzi \& Losardo, 2015). Asimismo, la intensidad del depósito de cenizas volcánicas reforzó la sensación de desazón existente entre las poblaciones afectadas. Esta situación motivó la intervención del Estado, a través de diversas acciones, muchas de ellas enfocadas en la ganadería, por su importancia en la economía y la dinámica social local (Álvarez Sánchez \& Ejarque, 2012). Entre ellas, se encontraron las políticas de repoblamiento ganade- ro. Este tipo de políticas han sido implementadas en diferentes lugares del mundo como estrategias para enfrentar, mitigar y/o prevenir los efectos de desastres y/o como mecanismo para reducir la pobreza y contribuir a los ingresos de familias rurales pobres. Sobre ellas, se han analizado especialmente sus efectos en términos de contribuciones socioeconómicas y las dificultades productivas- ambientales que pueden generar o tener que afrontar (Heffernan et al., 2001; Heffernan \& Rushton, 2001; Louwrens, 2001; Arasio, 2004; Ojala et al., 2010; MacDonald et al., 2011; March, 2011). Sin embargo, la mayoría de estos programas no han trabajado con recursos genéticos locales porque la tendencia general es hacia la promoción y concentración en razas comerciales (Gura, 2007), las de tipo criollo no suelen tener reconocimiento como raza ni recurso a promover desde la política pública (FAO, 2007) y no consideran las recomendaciones de organismos internacionales acerca de que la introducción de especies contemple las condiciones agroecológicas actuales y futuras (FAO, 2015).

Este artículo propone analizar la iniciativa de Repoblamiento con Cabras Criollas Neuquinas implementada en la provincia de Río Negro (Patagonia Argentina). Específicamente se busca describir las diferentes instancias de su desarrollo según la participación social y la articulación interinstitucional; identificar las potencialidades, dificultades y desafíos que presenta este tipo de política en un contexto de desastre natural; y examinar sus posibles efectos en cuanto a la adaptación y resiliencia, como condición de la población y las políticas frente a las variaciones en las condiciones ambientales

Para ello, la investigación retoma el enfoque del ciclo de las políticas públicas para considerar, en este estudio, tres fases de análisis: el diseño, la im- 
plementación y la evaluación (Tamayo Sáez, 1997; Lahera, 2004) ${ }^{1}$. En cada una de ellas se reconstruirá la articulación entre los diferentes organismos del Estado; se identificará el modo de participación de los productores y sus organizaciones; y se comprenderá los vínculos entre los conocimientos científicos, los saberes locales y las prácticas en el territorio.

\section{Sobre la investigación: enfoque y estrategia metodológica}

El análisis de las políticas de repoblamiento ganadero frente a desastres naturales puede inscribirse dentro del creciente campo de los estudios ambientales, en el cual se ha desarrollado una diversidad de perspectivas. Mientras en el pasado predominaron enfoques estáticos, funcionalistas o que sólo abordaban algún componente de la relación sociedad-naturaleza, en la actualidad se destaca el abordaje integrado, que considera la variabilidad espacio- tiempo, la interacción entre factores estructurales y la agencia social a distintas escalas (Lampis, 2013). En este último enfoque, el Estado ocupa un rol importante al delinear las $m a$ cropoliticas de gestión ambiental en sus territorios (Alimonda, 2005).

Para comprender las formas en que el Estado interviene en las cuestiones ambientales, esta investigación propone un diálogo con algunas concepciones clásicas de las ciencias políticas sobre el análisis de las políticas públicas. A raíz del reconocimiento de las dificultades al interior del Estado en el logro de un adecuado funcionamiento de las políticas se han desarrollado modelos para su análisis. Si bien los modelos secuenciales han sido objeto de críticas debido a su tendencia a una visión fragmentada, actualmente sirven de base para abordajes que contemplan la complejidad del proceso (Tobías, 2017). Por ello, se consideran analíticamente tres fases del ciclo de las políticas públicas que no necesariamente son consecutivas ni lineales, sino que puede haber retroalimentaciones y revisiones en función de lo acontecido en cada una (Figura 1). Además, existen procesos de definición del problema, la toma de decisión para su inclusión en agenda, los programas y las normas que se definen, las acciones y vínculos que los organismos y actores sociales construyen según los fines, objetivos, prioridades y principios de acción establecidos (O’Donnell, 2004; Lattuada et al., 2015).

La primera fase es la de formulación o diseño, en la que se determina una cuestión socialmente problematizada (Oszlak, 2009), es decir, se define un problema social que debe ser considerado en la agenda política y ser resuelto con la toma de posición e intervención de organismos del Estado (Oszlak, 1980). En la definición de las políticas y sus objetivos operan tanto ideas como intereses, que son objeto de disputas y negociaciones entre distintos actores sociales y unidades estatales. Según Scoones (1999), los expertos suelen tener un rol protagónico en las discusiones ambientales y, además pueden funcionar como mediadores sociales; es decir, intercediendo, vinculando y/o representando los intereses de dos partes pertenecientes a distintos ámbitos de la vida social. En relación con las polí-

\footnotetext{
${ }^{1}$ La literatura del campo establece múltiples formas y cantidades de definir las fases del ciclo para su análisis. Para este artículo elegimos una
} versión simplificada considerando solo tres etapas, aunque la primera incluye el origen que suele ser analizada de forma diferenciada (Lahera, 2004). 
ticas públicas, los mediadores pueden ser tanto los tecnócratas que intervienen en la definición de las normas, como los operadores sectoriales que actúan sobre el cambio, según los conocimientos y esquemas normativos desarrollados por los anteriores (Cowan Ros \& Nussbaumer, 2011).

La segunda fase, la implementación, es cuando se ejecuta el diseño y entran en juego tanto los actores sociales presentes en la etapa anterior como nuevos actores que se suman durante las tareas desarrolladas. En esta instancia se deben considerar las capacidades de los Estados y sus dirigentes para disponer de los recursos necesarios, generar apoyo interno y social y sortear la complejidad de las estructuras gubernamentales. Frecuentemente, los organismos poseen recursos y poder (posibilidades de coerción, información, legitimidad y bienes materiales) que no son suficientes para actuar de manera autónoma. Por ello, generalmente recurren al trabajo conjunto, a partir de relaciones formales interinstitucionales y a vínculos fuertes (relaciones generadas por la cercanía, la amistad o los lazos familiares- Granovetter, 1983). Así, el funcionamiento real de las instituciones del Estado y sus relaciones pueden ir más allá de los mecanismos y normativas formales, considerando que las políticas públicas se construyen y sostienen en los territorios, a través de cómo se amoldan a dichos espacios y al poder de intervención de los actores locales en esos procesos (Tobías, 2017).

La tercera fase es la evaluación, la cual implica no sólo un relevamiento puntual con una metodología sistemática y análisis de datos sobre los efectos de la política pública una vez implementada (Toledo, 2015), sino también una evaluación permanente a lo largo del proceso, generando información para reconocer nuevas demandas, oportunidades y con ellas reorientar las acciones. En la primera es fre-

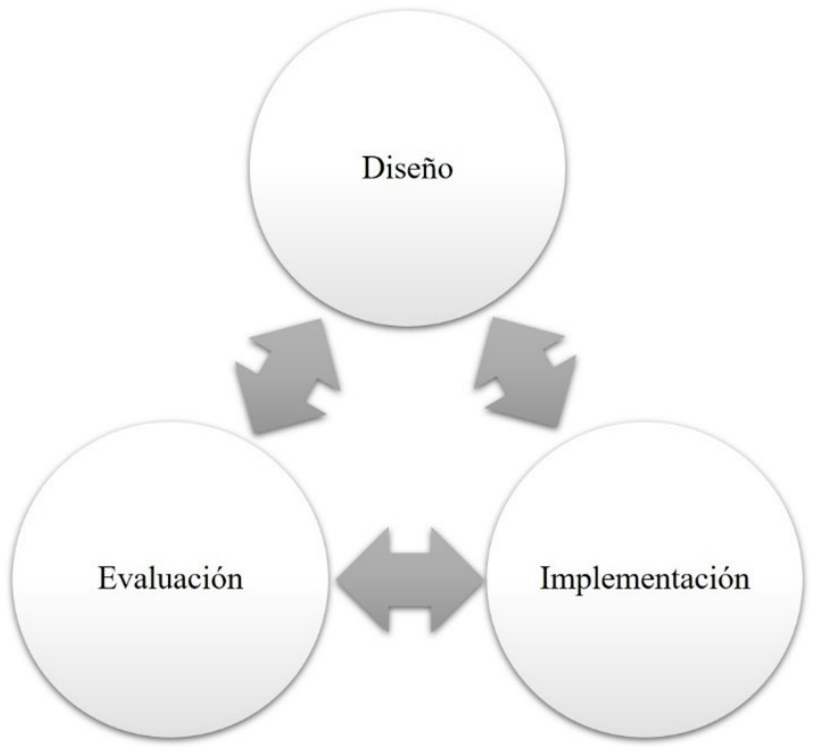

FIGURA 1 - Esquema del ciclo de las políticas públicas.

FUENTE: Elaboración propia en base a bibliografía. 
cuente la aplicación de estrategias más estructuradas y sistemáticas para la obtención de datos e indicadores concretos de acuerdo a ciertos objetivos, recurriendo muchas veces a métodos científicos. En la segunda, la información se recolecta de modo indirecto, selectivo y parcial (Tamayo Sáez, 1997). Además, la evaluación puede ser interactiva mediante un "proceso de investigación participativa que analiza la organización, el funcionamiento y desarrollo de un programa en relación con sus objetivos, las expectativas de sus participantes y los resultados obtenidos" (Lahera, 2004, p. 23).

Bajo este enfoque teórico-analítico de las políticas públicas, la estrategia metodológica se basó en la utilización de datos cuantitativos y cualitativos, combinando múltiples fuentes de datos primarios y secundarios. Por un lado, se recurrió al análisis de documentos (Bowen, 2009), generados en el marco de la iniciativa en diversos momentos: notas de síntesis sobre reuniones con productores y técnicos, formularios de presentación de proyectos, artículos de difusión, informes institucionales, noticias periodísticas, correos electrónicos, entre otros. Estos documentos representan y materializan información y conocimientos, a través de la utilización de un código y lenguaje común, permiten transmitir aquello procesado en los actores que los elaboran. Luego de la compilación y sistematización, se realizó un análisis de contenido de tipo cualitativo, identificando los enunciados presentes tanto en el sentido literal como interpretativo y considerando el contenido latente y el contexto presente en los textos (Bowen, 2009).

Por otro lado, se desarrollaron entrevistas conversacionales informales (Jamshed, 2014) con el equipo técnico que participó del proyecto en el marco de reuniones de síntesis y discusión de los resultados. El carácter emergente y flexible de estas entrevistas permitió incorporar nuevas fuentes de datos y dimensiones de análisis. La información obtenida se sistematizó y analizó mediante una matriz cualitativa.

Por último, se reprocesaron datos provenientes de dos instrumentos de la evaluación de la iniciativa: la encuesta "Relevamiento sobre el Repoblamiento con Cabras Criollas Neuquinas 2016-2017” (en adelante Relevamiento 2017) y el Taller "Encuentro de Saberes Sur y Norte" en 2017. E1 Relevamiento 2017 fue una evaluación cuantitativa de indicadores productivos a partir encuestas realizadas entre los meses de noviembre 2016 y febrero 2017 a 69 pequeños productores de los proyectos de repoblamiento en 2014 y 2015 (77\% del total de participantes). Se obtuvieron datos sobre sus unidades domésticas -entendidas como el conjunto de personas que comparten la vivienda, la comida y que cooperan en la obtención de ingresos (Pérez Centeno, 2007)- y permitió tener una estimación de la eficiencia reproductiva de los diferentes recursos genéticos y comparar sus resultados.

El taller tuvo como objetivo realizar una evaluación compartida de la experiencia de reintroducción de las cabras y participaron 51 productores rionegrinos beneficiarios de los proyectos, 4 productores neuquinos que vendieron las cabras para el repoblamiento e integrantes del equipo técnico. A partir de la observación participante, el registro de las actividades y el material audiovisual generado, mediante un análisis cualitativo, se obtuvo información sobre las valoraciones y perspectivas sobre el repoblamiento. 


\subsection{El caso de estudio}

La ganadería es una de las principales actividades productivas en las tierras secas patagónicas. Específicamente, la iniciativa de repoblamiento ganadero con Cabras Criollas Neuquinas ${ }^{2}$ (Figura 2) se concentró en la región Línea Sur, que comprende casi la mitad de la superficie del sur de la provincia de Río Negro, y se encuentra distribuida en seis departamentos: 9 de Julio, Valcheta, Pilcaniyeu, 25 de Mayo, Ñorquinco y El Cuy (Figura 3).

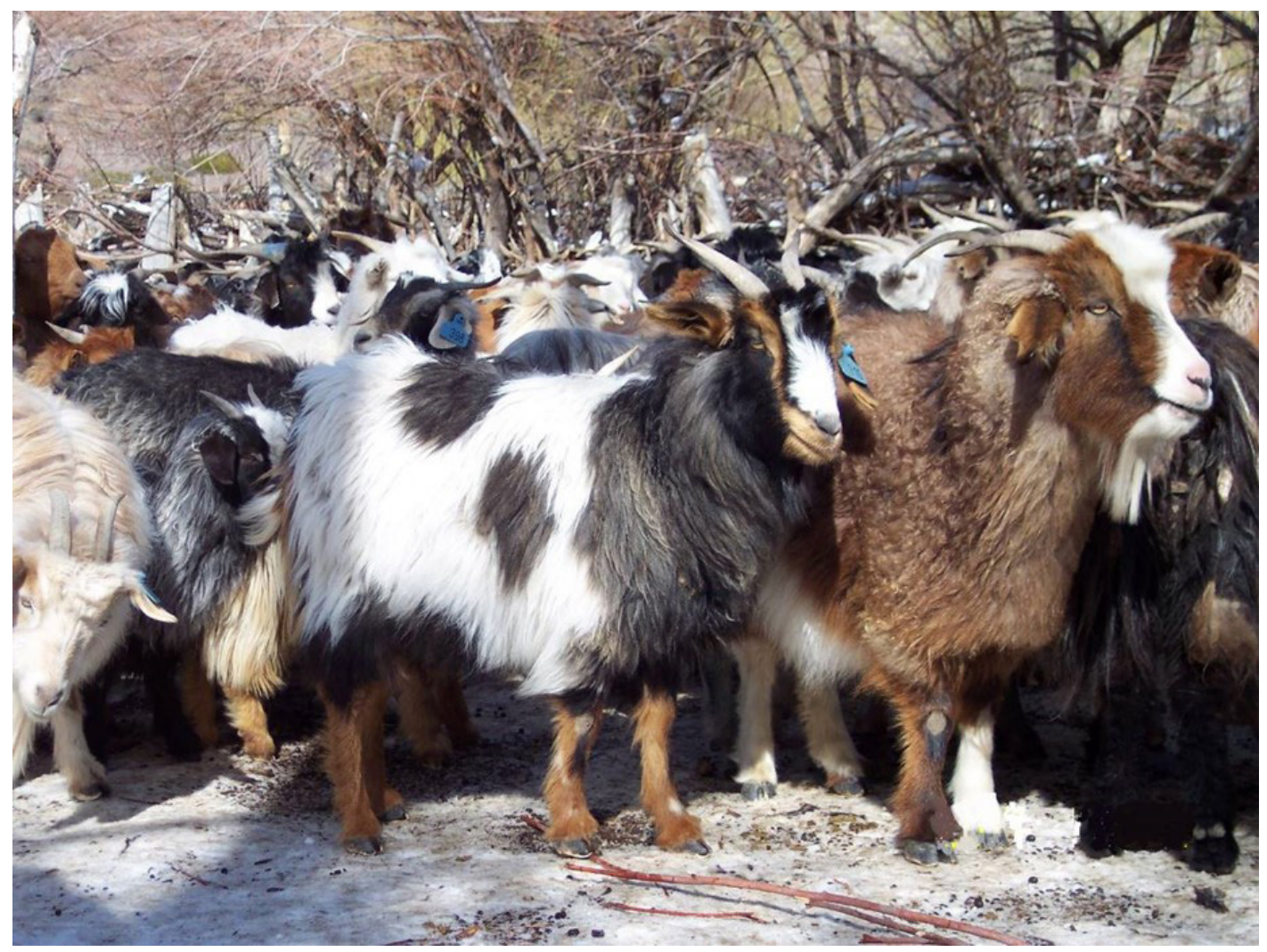

FIGURA 2 - Cabras Criollas Neuquinas.

FUENTE: Archivo personal de Marcelo Pérez Centeno (2004).

2 "Se define como un animal mesolíneo, con vellones de doble capa de fibras, una basta exterior y otra de fibra finas o down, de perfil recto, orejas medianas y levemente caídas, con baja frecuencia de mamelas y cuernos usualmente arqueado-espiralados. Las hembras alcanzan peso adulto de $40 \mathrm{~kg}$ y los machos de $64 \mathrm{~kg}$. El ecotipo 'Pelado' presenta pelo corto y capas de colores variados mientras que el 'Chilludo' presenta pelo largo predominantemente de color blanco" (Lanari, 2004, p. 187). 


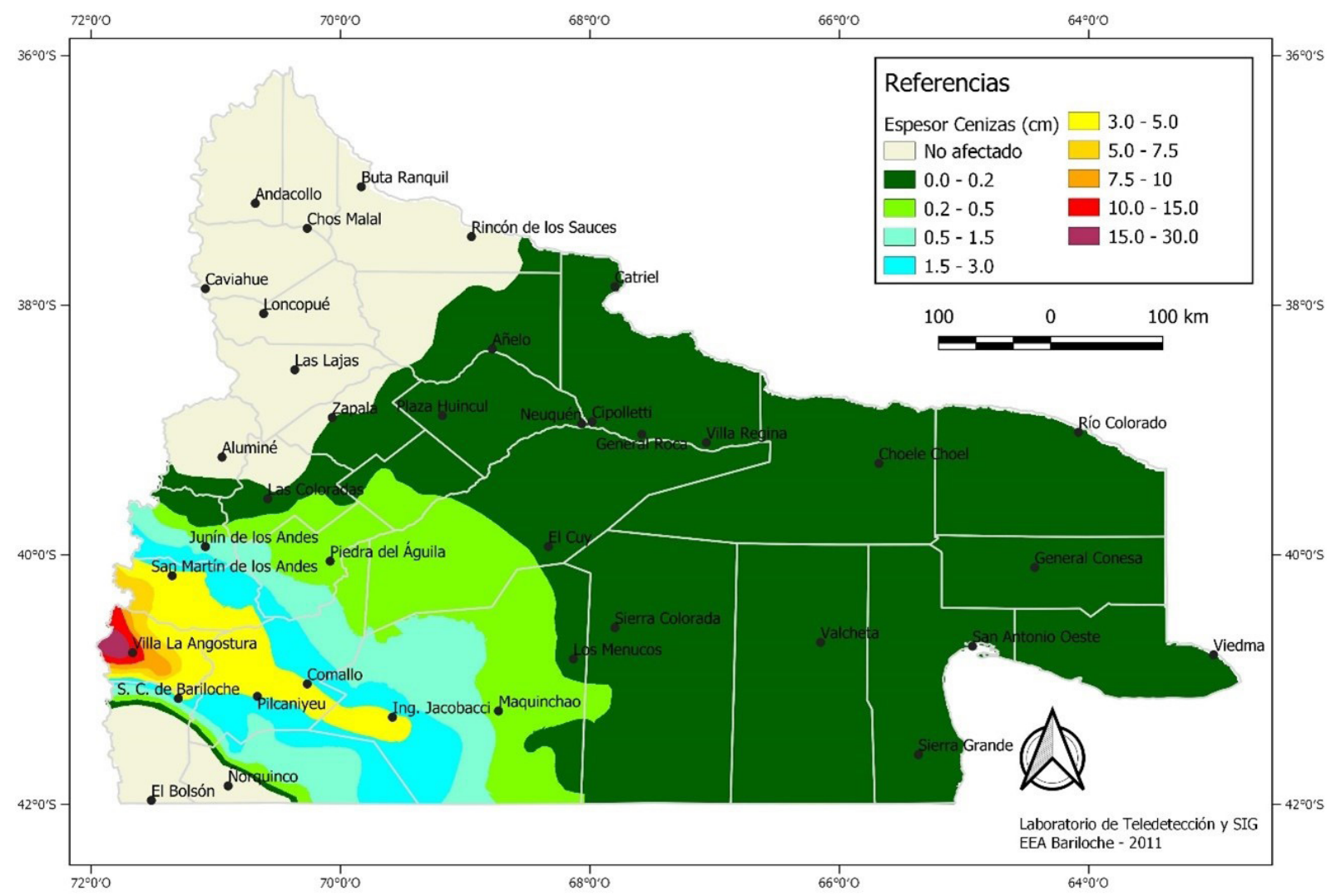

FIGURA 3 - Área afectada por cenizas en las provincias de Río Negro y Neuquén (Patagonia, Argentina), según espesor de las cenizas medida en centímetros.

FUENTE: Gaitán et al. (2011).

Históricamente, la ganadería extensiva ovina $\mathrm{y}$, en menor grado, caprina ha sido la actividad predominante de la región y la dinámica demográfica ha estado estrechamente vinculada a los ciclos económicos de dicha actividad (Steimbreger \& Kreiter, 2010). Si bien la misma se remonta a las economía de los pueblos originarios que se dedicaban a la cría de animales, es a fines del siglo XIX que esta actividad se vuelve dominante gracias a las posibilidades de colocación de las fibras a nivel internacional por la demanda europea, el traslado de ovinos de la región pampeana, la apropiación de las tierras por parte del Estado argentino y la conformación de grandes latifundios y el desarrollo del ferrocarril "Línea Sur" (Bandieri, 2009; Steimbreger \& Kreiter, 2010).

En la actualidad, los pequeños productores representan el 62\% (1.411) de las explotaciones 
agropecuarias de la región pero solo tienen el 25\% (1.951.550 hactáreas) de la superficie ocupada en el agro (de Obschatko et al., 2007) ${ }^{3}$. En su mayoría tienen formas de tenencia precaria, son ocupantes o adjudicatarios de tierras fiscales y aparceros (Bendini \& Steimbreger, 2010). El trabajo productivo se realiza, predominantemente, con mano de obra familiar. El destino principal de su producción es la venta de lana ovina y de pelo caprino (mohair) y en, menor medida, carne, aunque son claras las dificultades en el acceso al circuito de comercialización. Una parte de estos productos también se destina al consumo familiar (Bendini \& Steimbreger, 2010).

En las últimas décadas, la caída del precio internacional de la lana y el deterioro ecológico generado por la desertificación de las tierras y las recurrentes sequías (Bran et al., 2011) disminuyeron la productividad ovina y el stock ganadero. Estos procesos trajeron aparejada una continua descapitalización y pérdida de ingresos, que en algunos casos motivó la migración por motivos laborales (Bendini \& Steimbreger, 2010) o para el acceso a otros ingresos y servicios, como educación, salud, cobro de jubilaciones y pensiones.

Esta crítica situación social y productiva en la Línea Sur se vio agravada por la erupción del Complejo Volcánico Caulle Puyehue en junio de 2011 (Easdale et al., 2011). Debido a su cercanía, la altura de la columna de gases y cenizas (que llegó a los 14.000 metros), la duración temporal y la predominancia de vientos del cuadrante oeste, gran parte de las cenizas emanadas se depositaron en el territorio argentino (Gaitán et al., 2011). En
Río Negro, el 97\% (19.700.000 hectáreas) de la superficie recibió cenizas, siendo Norquinco, Pilcaniyeu, 25 de Mayo y Bariloche los departamentos más afectados (Figura 3). Villagra et al. (2011) estiman en 1515 los productores afectados, siendo $60 \%$ del área de Ingeniero Jaccobacci y Comallo y, mayoritariamente, pequeños productores.

El depósito de cenizas generó impactos en las redes de servicios y comunicaciones, turbidez en las fuentes de agua, cubrimiento de los pastizales y disminución de la disponibilidad forrajera (Irisarri et al., 2012; Wilson et al., 2013). Estos hechos provocaron mortandad de animales, consecuencias negativas en la salud de los animales (desgaste prematuro de dientes, problemas respiratorios y gastrointestinales) y deterioro en la calidad de las fibras obtenidas. Por la cantidad de cenizas y el clima semiárido la presencia en la región fue prolongada (Ghermandi \& González, 2012).

Frente a esta situación, el Estado intervino de diversas maneras. En el plano legislativo, se aplicó la ley Nacional $N^{\circ} 26.509$ de Emergencia Agropecuaria que permitió la disposición de créditos y subsidios especiales y la prórroga o condonación de créditos y cargas impositivas (Argentina, 2005). El gobierno rionegrino estableció su equivalente para los impuestos provinciales y locales (Río Negro, 2011). Fue inmediata la llegada de agua mineral y barbijos para la población, las medidas para el incremento de los beneficios de la seguridad social (asignaciones familiares, asignación universal por hijo, entre otros) y acuerdos para evitar los despidos de trabajadores (Álvarez Sánchez \& Ejarque, 2012).

\footnotetext{
${ }^{3}$ Definen a los pequeños productores de esta zona como aquellos que dirigen una explotación agropecuaria; trabajan de manera directa en la explotación; no contratan trabajadores no familiares remunerados permanentes; no tienen como forma jurídica la "sociedad anónima" o "en comandita por acciones"; y poseen una superficie total de hasta 5000 ha.; y hasta 500 unidades ganaderas.
} 
A los fines de evaluar la situación y el trabajo en la zona, se conformaron los Comités de Emergencia (COEM) en cada municipio, con representantes de diferentes organismos e instituciones públicas y de la sociedad civil. Los gobiernos también realizaron la compra de fardos y cereales para suplementar la alimentación de los animales y proyectos para mejorar la captación de agua, la comunicación y provisión de electricidad. En agosto de 2011, se sancionó la ley Nacional $\mathrm{N}^{\circ} 26.698$, de alcance patagónico, destinada a crear un programa para recuperar el stock ganadero de los pequeños productores afectados (Argentina, 2011b).

En este contexto de acción del Estado, se inscribieron una serie de proyectos de repoblamiento ganadero con ovinos y caprinos de raza Angora, financiados en el marco de las leyes $\mathrm{N}^{\circ} 26.680 / 2011$ para la producción ovina y $\mathrm{N}^{\circ} 26.141 / 2006$ para la producción caprina y de proyectos internacionales gestionados por la Unidad para el Cambio Rural (Argentina, 2006, 2011a). Entre ellos, se encuentra la iniciativa de repoblamiento con Cabras Criollas Neuquinas, analizada en este artículo.

\section{El origen y el diseño de la iniciativa de repoblamiento}

La iniciativa de repoblamiento con Cabras Criollas Neuquinas surge como consecuencia de la crítica situación ambiental y productiva que se había generado, principalmente, a partir de la caída de las cenizas volcánicas. En las reuniones en los COEM había quedado en evidencia la gravedad de los efectos en términos sociales y productivos. En Comallo se registraron pérdidas promedio del 50\% y en Ingeniero Jacobacci del orden del 25\% (Easdale et al., 2011), aunque técnicos del terreno estimaban números aún mayores, que llegaban a alcanzar al $70 \%$. Como consecuencia de la mortandad, el 70\% de los productores no alcanzaba a tener la cantidad de animales necesarios -estimado en un mínimo de 150 rumiantes menores- para autoabastecerse de carne (Muzi \& Losardo, 2015). Esta dificultad se agravaba porque el modelo productivo dominante se había basado en la cría de especies especializadas en fibras, pero con poca capacidad para la generación de carne. La suma de estos factores claramente aumentó la vulnerabilidad de los productores.

Ante estos diagnósticos, se promovió la realización de unas jornadas en Sierra Colorada, el 5 y 6 de diciembre de 2011, para debatir posibles propuestas productivas para enfrentar los efectos del desastre natural. En ellas participaron organismos públicos nacionales, provinciales y municipales, organizaciones de pueblos originarios y de la agricultura familiar. Las jornadas mostraron una diversidad de ideas e intereses respecto a las propuestas productivas, según se han plasmado en el documento "Propuesta de Políticas Públicas para la Región afectada por sequía y cenizas". De modo esquemático, una mayoría de los participantes promovió políticas centradas en el combate de la emergencia, como la suplementación alimentaria para el ganado; mientras que otro grupo proponía avanzar en una segunda etapa del trabajo frente a emergencias, en la recuperación o rehabilitación inmediata (Caballeros Otero \& Zapata Marti, 1994), a través del repoblamiento ganadero. Para este último grupo, el repoblamiento era necesario porque la ganadería es parte de la tradición y del modo de vida de los pequeños productores de la región (Muzi \& Losardo, 2015). Sin embargo, como suele suceder con las políticas de repoblamiento, ésta fue objeto de cuestionamiento (Heffernan \& Rushton, 2001), 
basados en una perspectiva centrada en los recursos naturales, al sostener que podía agravar el deterioro ambiental y la sobrecarga animal.

Las propuestas del primer grupo, de combate a la emergencia, contaron con mayor apoyo institucional y político y consenso social. Pese a ello, el segundo grupo avanzó con la elaboración de proyectos para financiar el repoblamiento, aunque surgieron nuevas divergencias en la forma de lograrlo: algunos buscaban continuar con el modelo productivo dominante y desarrollar el repoblamiento con ovinos y Cabras Angora para obtener fibras de calidad; y otro grupo promovió la iniciativa de reintroducir las Cabras Criollas Neuquinas.

Los argumentos del repoblamiento con Cabras Criollas Neuquinas se basaban en la potencialidad que éstas tenían no sólo para lograr la recomposición del stock ganadero sino también alcanzar la seguridad alimentaria ${ }^{4}$ mediante el fortalecimiento del consumo de carne, debido a su prolificidad. Subsidiariamente, esas cabras podrían contribuir a generar ingresos adicionales mediante la venta de carne y se preveía que su adopción no implicaría modificaciones sustanciales en la gestión de los recursos ganaderos, logrando ser aceptados social y culturalmente por parte de los productores. Como sostiene March (2011), las respuestas más eficientes frente a los desastres naturales son aquellas que permiten que las poblaciones puedan recuperarse de la emergencia y estar mejor preparadas para eventos futuros, ya sea en términos de mejoras de su calidad de vida como de las condiciones ambientales. En el origen de la idea de repoblamiento con Cabras Criollas Neuquinas se encuentran recursos, saberes y prácticas productivas locales, cuyo conocimiento se encontraba sistematizado por organizaciones científico- tecnológicas de la región. Sus potencialidades como recurso genético y raza local ${ }^{5}$ se conocían a raíz de su estudio, desde mediados de la década de 1990, por parte de distintos organismos de ciencia y técnica del Instituto Nacional de Tecnología Agropecuaria (INTA) -la Estación Experimental Agropecuaria (EEA) Bariloche, la Agencia de Extensión Rural de Chos Malal, y el Instituto de Investigación y Desarrollo Tecnológico para la Agricultura Familiar de la Región Patagonia (IPAF Patagonia)-, el Ministerio de Producción de la provincia de Neuquén y la Subsecretaría de Agricultura Familiar (SSAF) . En particular, el INTA Bariloche había incorporado en 1998 ejemplares en su campo experimental (Anexo Pilcaniyeu), lo cual permitió contar con registros de su performance de más de 15 años. Estos análisis demostraban la rusticidad, capacidad de adaptación y productividad en fibras, carne y leche de las Cabras Criollas Neuquinas (Lanari, 2004) ${ }^{6}$.

Las investigaciones en el norte neuquino demostraban que, desde su introducción en la época colonial,

\footnotetext{
${ }^{4}$ La seguridad alimentaria, según la definición de FAO de 1974 es el derecho de las personas a la alimentación adecuada y suficiente según los parámetros culturales y nutricionales vigentes en cada sociedad. Por las transformaciones conceptuales y los usos políticos del término, se habla de soberanía alimentaria, que considera también la capacidad y acción de los pueblos para definir cómo se obtienen los alimentos y las políticas para desarrollarlos (Carballo, 2011), pero ambas no son contradictorias.

${ }^{5}$ Son razas que fueron adaptadas a un hábitat específico y seleccionadas según preferencias culturales de una comunidad o grupo étnico (LPP et al., 2010). La definición de la cabra criolla neuquina como una raza local fue definida por Lanari (2004).

${ }^{6}$ El 86\% de las Cabras Criollas Neuquinas tienen una doble capa de fibra en el vellón que los protege menor frente al frío y de la cual se puede obtener cashmere, una fibra de alto valor comercial, pero con escaso aprovechamiento local. Las madres son prolíficas (140\% de parición y fertilidad encima del $80 \%$ ) y buenas para la crianza, aun en partos múltiples. Por la alta proporción de proteínas y grasas de su leche crecen rápido. No tienen problemas sanitarios relevantes.
} 
las Cabras Criollas Neuquinas se incorporaron como animales de crianza por parte de las comunidades originarias y, luego, por la agricultura familiar que repobló la región. Estas son un recurso preservado y conservado hace siglos por su adaptación a la estepa patagónica. Los productores neuquinos realizan la trashumancia entre campos de veranada y de invernada $\mathrm{y}$, en esos movimientos, estas cabras son trasladadas con escaso alimento pese a que se encuentran en los momentos de máximo requerimiento nutricional (fin de la gestación y preservicio). Aún en esas condiciones, engordan, tienen crías y muchas veces son melliceras (Pérez Centeno, 2007).

Las Cabras Criollas Neuquinas no sólo habían estado en el norte neuquino. La historia oral y escrita local reconoce su presencia en la Línea Sur antes de la llegada de Ovinos Merino y de Cabras Angora a fines del siglo XIX (Moldes et al., 2003). Entre los pequeños productores, estas especies coexistieron hasta avanzado el siglo XX y, paulatinamente, las criollas se abandonaron para priorizar las exóticas, productoras de fibras.

Cuando cayeron las cenizas volcánicas, las Cabras Criollas Neuquinas del predio del INTA estaban preñadas, como la mayor parte de los animales de la región. Los investigadores locales decidieron no suplementar su alimentación, para evaluar el comportamiento y la productividad bajo las cenizas. Los resultados de esta experiencia demostraron nuevamente la fortaleza y resiliencia de este recurso genético local (Lanari et al., 2012).

Asimismo, en los años de la sequía (2007-2011) algunos productores rionegrinos habían vuelto a adquirir Cabras Criollas Neuquinas y las valoraron en el contexto de las cenizas por su fortaleza y resistencia. En esos casos, las cabras tuvieron similares resultados que en el predio del INTA: baja o nula mortandad, bue- nos índices de señalada y subsistencia sin necesidad de forraje en el momento de la emergencia (Lanari et al., 2012). También resaltaban la capacidad materna y el buen desempeño en la crianza a pesar de los predadores. Los productores llegaron a afirmar que "las Criollas salvaron el año".

De esta manera, la iniciativa de repoblamiento con Cabras Criollas Neuquinas se consolidó a partir de un saber compartido, construido a partir de los conocimientos científicos originales, las experiencias individuales y colectivas y los saberes locales (Landini, 2010), en virtud del desempeño observado durante la emergencia (capacidad de adaptación y tasa de reproducción) comparado con otras especies y/o razas presentes en el área.

En una primera instancia, un equipo técnico conformado por especialistas de diferentes organismos comenzó a trabajar en la iniciativa, esbozando las primeras líneas. Luego, se contactaron referentes locales y de organizaciones de productores para consensuar los lineamientos básicos. Articulando con el Área de Desarrollo Social de los municipios se hicieron convocatorias radiales para difundir y buscar posibles interesados en participar de los proyectos. A partir de ello, se realizaron reuniones con los productores en las que se pudieron evidenciar distintas posturas. Quienes tenían experiencia en cría de Cabras Criollas Neuquinas avalaron rápidamente la propuesta y otros plantearon sus dudas y reparos, en palabras de un productor: "el discurso muy bonito.... ahora vamos a ver" (Productor, Reunión informativa, Comallo, 2014). Sin embargo, y probablemente impulsados por la necesidad, muchos productores decidieron sumarse.

La iniciativa consistió en un crédito que proveyó 30 Cabras Criollas Neuquinas (29 hembras y un macho) a cada productor, se cubrían gastos de logística y se brindarían capacitaciones sobre manejo, 
reproducción y comercialización. El financiamiento contemplaba dos años de gracia, a partir del cual cada productor devolvería el capital recibido a razón de 10 hembras jóvenes por año. Los animales de las devoluciones se utilizarían para entregarlos a nuevos productores favoreciendo el sostenimiento y expansión del repoblamiento en el largo plazo, sin necesidad de continuos financiamientos externos.

Definidos los objetivos a implementar en la Línea Sur, se determinó que las cabras provendrían del norte de la provincia de Neuquén. Además de sus características mencionadas, la utilización de estas cabras era favorable frente a la falta de oferta de merinos u otras cabras en zonas cercanas y la imposibilidad de traer animales de otras áreas de Argentina debido a la existencia de una barrera sanitaria que no permite el movimiento de hacienda de norte a sur. Para ello, el equipo técnico viajó con productores y representantes de las organizaciones al norte neuquino y, con la colaboración de técnicos del área lograron identificar que había animales disponibles y productores dispuestos a venderlos. De esta manera, la iniciativa también podía generar impactos positivos en la economía local del norte neuquino y el desarrollo de vínculos entre productores de un mismo estrato.

Con estas definiciones y avances de diseño, la formulación de los proyectos para la presentación de subsidios quedó a cargo de la SSAF, organismo enfocado en la elaboración de intervenciones en el terreno. Según las normativas de los organismos de financiamiento, los beneficiarios debían ser organizaciones de productores con personería jurídica y/u organismos estatales. En Ingeniero Jacobacci se unieron a la Cooperativa Ganadera Indígena y en Comallo con el municipio debido a la ausencia de organizaciones bajo aquella figura. Éstas se comprometieron, desde un inicio, a tareas fundamentales: recibir los fondos, garantizar su destino, acompañar en la logística, participar del seguimiento y evaluación, recibir y gestionar los animales de devolución y facilitar la venta de excedentes cárnicos si la reintroducción resultaba exitosa.

Como se registra, el diseño de esta iniciativa fue participativo e interinstitucional, basado en conocimientos científicos desarrollados en el terreno y saberes locales sobre un recurso ganadero que permitía responder a los intereses de recomposición de stock y seguridad alimentaria de los productores. Los expertos, lejos de obrar con visiones pragmáticas y basadas solo en su conocimiento técnico (Azuela, 2006) tomaron dichos antecedentes. Actuaron como mediadores para dar forma a la propuesta, articulando participantes de distintas regiones y organismos con diferentes propósitos y fines en pos de esa idea común, pese a los prejuicios y posiciones contrarias que podían existir en el territorio.

\section{Desafíos en la implementación de la iniciativa}

La implementación de la iniciativa contempló resolver problemas, desarrollar acciones y trabajo participativo en tres puntos centrales: el financiamiento, la selección de los participantes y la logística.

En cuanto al financiamiento, en Argentina existen diferentes organismos que otorgan fondos para iniciativas en el medio rural. Sin embargo, ya en la reunión inicial en Sierra Colorada se avizoraba cierta reticencia a financiar el repoblamiento y especialmente con Cabras Criollas Neuquinas, probablemente por los prejuicios respecto al daño ambiental que se les atribuye a las cabras y la subvalorización de dicha raza y de los recursos zoogenéticos locales en el plano técnico nacional 
(Martínez, 2015). Inicialmente, el repoblamiento logró el apoyo de dos organismos- Ministerio de Desarrollo Social y de Trabajo- que no suelen financiar proyectos productivos agrarios, pero esta iniciativa resultó, particularmente, de interés por su aporte social (por la seguridad alimentaria) y la ocupación en el campo (por el autoempleo familiar). Los proyectos correspondientes a estos financiamientos se implementaron a partir de 2014, incluyendo 60 productores en áreas de influencia de los Municipios de Ingeniero Jacobacci y Comallo (Tabla 1).

A partir de los indicios de buena adaptación de las cabras y luego de un reconocimiento que la iniciativa obtuvo en 2015 por parte del Fondo Regional de Tecnología Agropecuaria (Fontagro), fuentes de financiamiento históricamente ligadas o específicas del sector agropecuario decidieron apoyar nuevos proyectos de repoblamiento con Cabras Criollas Neuquinas. Estos, además de sumar productores, posibilitaron ampliar el alcance territorial hacia otras áreas de la Línea Sur e incorporar nuevas organizaciones de productores familiares (Tabla 1).

Los criterios priorizados para la selección de los beneficiarios fueron definidos en forma consensuada entre las organizaciones de productores y el equipo técnico. Estos fueron: residencia rural; presencia de jóvenes y adultos jóvenes en el grupo familiar; experiencia en el manejo de cabras; voluntad y capacidad para el trabajo asociativo y la participación en reuniones y capacitaciones; tener menos de 150 animales (la cantidad mínima que permite garantizar la seguridad alimentaria); y contar con cierta infraestructura predial para recibir los animales (cobertizos y corrales). Con este perfil de productores se buscaba, también, contribuir con otros objetivos de largo plazo: la renovación generacional de los pequeños productores, el arraigo rural y la promoción del fortalecimiento organizativo,

TABLA 1 - Proyectos de repoblamiento con Cabras Criollas Neuquinas implementados en la Provincia de Río Negro (Patagonia, Argentina) entre los años 2014 y 2018.

\begin{tabular}{|c|c|c|c|c|c|}
\hline Año & Localidades & Cantidad de productores & Organizaciones a cargo & Fuente de financiamiento & Monto \\
\hline \multirow{2}{*}{2014} & $\begin{array}{l}\text { Ingeniero } \\
\text { Jacobacci }\end{array}$ & 30 & $\begin{array}{l}\text { Cooperativa Ganadera } \\
\text { Indígena }\end{array}$ & $\begin{array}{l}\text { Ministerio de Desarrollo } \\
\text { Social de la Nación }\end{array}$ & U\$S75.725 \\
\hline & Comallo & 30 & Municipio de Comallo & $\begin{array}{l}\text { Ministerio de Trabajo de la } \\
\text { Nación }\end{array}$ & U\$S75.000 \\
\hline 2015 & $\begin{array}{l}\text { Ingeniero } \\
\text { Jacobacci }\end{array}$ & 30 & $\begin{array}{l}\text { Cooperativa Ganadera } \\
\text { Indígena }\end{array}$ & $\begin{array}{l}\text { Fondo Fiduciario } \\
\text { Hidrocarburífero de la } \\
\text { Provincia de Río Negro }\end{array}$ & U\$S75.550 \\
\hline 2017 & $\begin{array}{l}\text { Comallo, } \\
\text { Mencué } \\
\text { y Laguna } \\
\text { Blanca }\end{array}$ & 35 & $\begin{array}{l}\text { Grupo de Productores de } \\
\text { Laguna Blanca y Mencué; } \\
\text { Comunidad Mencué }\end{array}$ & Ley Caprina Río Negro & U\$S109.666 \\
\hline 2018 & $\begin{array}{l}\text { Norquinco y } \\
\text { Mencué }\end{array}$ & 18 & $\begin{array}{l}\text { Grupo de Productores de } \\
\text { Laguna Blanca y Mencué; } \\
\text { Comunidad Mencué; } \\
\text { Cooperativa Peñi Mapuche }\end{array}$ & $\begin{array}{l}\text { Autofinanciamiento (con } \\
\text { devolución cabras 2014- } \\
\text { 2015) }\end{array}$ & $\begin{array}{l}\text { U\$S43.478 } \\
\text { (estimado) }\end{array}$ \\
\hline
\end{tabular}

FUENTE: Elaboración propia en base a fuentes documentales y entrevistas al equipo técnico. 
según se evidencia en las solicitudes de financiamiento de los proyectos.

La selección de los beneficiarios se formalizó a partir de un acta acuerdo que firmaron con las organizaciones y los organismos de financiamiento, donde se definieron los compromisos y responsabilidades de las partes:

- Los productores se comprometieron al cuidado de los animales, a participar de las capacitaciones sobre manejo y comercialización. Informalmente, los productores y sus organizaciones asumieron la obligación de designar a una persona para acompañar el proceso de compra y revisación de las cabras en el lugar de origen.

- Los financiadores cubrirían los costos de la compra de las cabras, transporte e insumos sanitarios y auditar los gastos.

- Los organismos técnicos se encargarían de realizar capacitaciones y el seguimiento del proyecto; y las organizaciones a realizar el manejo del proyecto.

En cuanto a la logística de compra y entrega de los animales, la iniciativa tuvo la complejidad de trabajar en dos áreas distantes a más de 1000 $\mathrm{km}$ y con una importante dispersión geográfica interna. Una vez asignados los fondos tuvieron que ser resueltos distintos problemas: definir cómo y dónde concentrar los animales en el norte, adquirir los permisos para la circulación de los animales, acordar el precio de venta y conseguir comprobantes de pago $^{7}$. Sobre este punto, además de los vínculos preexistentes con organizaciones y organismos del norte neuquino, fue central la aparición de un nuevo mediador social, un experto lego, productorcomerciante- transportista de la zona, que, gracias a sus vínculos fuertes, de confianza con los productores y otras personas de la zona pudieron resolver aquellos desafíos. Él coordinó las negociaciones con los productores por el precio, se ocupó de definir puntos de concentración de los animales y gestionó los comprobantes.

La mencionada distancia y el estado de los caminos dificultaron el traslado, pese a que se contrataron transportistas de confianza y que conocían el área. En los primeros dos proyectos no hubo inconvenientes, pero en 2015 el camión "quedó varado" y los animales tuvieron que soportar las duras inclemencias del frío invernal (Lanari et al., 2017). Si bien no hubo abortos ni muertes, el sufrimiento que generó el episodio afectó la adaptación y productividad.

Por último, la implementación del repoblamiento incluía la realización de capacitaciones sobre el manejo de Cabras Criollas Neuquinas. Sin embargo, y como se describen en el siguiente apartado, las evaluaciones en proceso mostraron que los productores no requirieron del aprendizaje de nuevas prácticas debido a sus saberes previos y la ausencia de particularidades en la cría de las criollas. De modo que el equipo técnico brindó asistencia en técnicas puntuales, especialmente en temas sanitarios dada la relevancia de esta temática para una evaluación positiva del programa y de la devolución del "crédito" de los animales (Ojala et al., 2010), y

7 Cabe aclarar que las economías de los pequeños productores en Argentina son mayormente informales, pese a algunos intentos de los últimos años por simplificar los procesos para adecuar normativas y mecanismos vigentes para las condiciones y características de estos productores. 
redirigió sus esfuerzos hacia otras capacitaciones, producto de nuevas demandas emergentes.

\section{Evaluación y nuevos desafíos}

Lejos de un enfoque que focaliza en la medición de impacto, la evaluación del repoblamiento fue procesual, promoviendo reflexiones e intercambios entre los participantes sobre el proceso y los resultados y buscando identificar oportunidades y nuevas demandas surgidas de la implementación. El equipo técnico realizó monitoreos continuos y seguimientos en el territorio, que contribuyeron a reorientar las actividades o los modos en que se estaban llevando a cabo. Por ejemplo, el cambio en las capacitaciones desde cuestiones de manejo hacia la elaboración de productos derivados de las cabras o solicitar nuevos financiamientos a partir de los resultados incipientes de los primeros proyectos.

La evaluación sistemática fue posible gracias al financiamiento obtenido a través de un reconocimiento de FONTAGRO en $2015^{\circ}$. La sistematización de los resultados se produjo a través de una metodología mixta de investigación que incluyó dos instancias de generación de datos empíricos. Por un lado, el Relevamiento 2017, un operativo de encuesta para analizar los resultados productivos del proyecto, conocer las valoraciones y la satisfacción de los productores, e identificar posibles líneas de continuidad. En esta instancia participaron 69 pequeños productores de los proyectos de $2014 \mathrm{y}$
2015 (los de 2017 y 2018 aún no fueron evaluados). Por otro, el Taller con productores de la Línea Sur y del norte neuquino en el que se trataron los mismos temas, se compartieron las experiencias vividas con el repoblamiento e intercambiaron saberes respecto a la esquila de las cabras (para lo cual se visitaron los campos de dos productores de Comallo).

La evaluación de 2017 mostró que, luego de 2 o 3 años de su recepción, $96 \%$ de los productores seguían conservando las cabras y que el stock ganadero se iba recuperando, aunque todavía seguía siendo bajo (en promedio, 191 unidades ganaderas ovinas $)^{9}$. La rusticidad, prolificidad y adaptación de las cabras se mostró rápidamente, inclusive con indicadores de crecimiento de stock y señalada superiores a otros rumiantes menores. Comparando los casos de productores que tenían tres especie (razas Cabras Angora y Criolla Neuquina y Ovinos Merino), entre 2015 y 2016, las Cabras Criollas Neuquinas incrementaron un $13 \%$ su stock, las Cabras Angora un 6\% y los ovinos disminuyeron su presencia (Tabla 2) ${ }^{10}$.

Asimismo, las criollas en dichos años superaron el $90 \%$ de señalada promedio y se encuentran por encima de los valores obtenidos por las otras dos especies /razas (Tabla 3).

Analizar individualmente los resultados de los tres primeros proyectos de repoblamiento permite observar particularidades para obtener aprendizajes sobre este tipo de políticas. Las tablas 4 y 5 sintetizan la evolución del stock de madres e índice de

\footnotetext{
${ }^{8}$ El proceso articulado de reflexión y evaluación procesual entre organismos técnicos y científicos permitió mostrar el carácter de innovación productiva de la iniciativa, debido a su utilización de recursos genéticos locales para la seguridad alimentaria y la adaptación al cambio climático.

${ }^{9}$ Para determinar la carga animal cuando están presentes diferentes especies, se establece un sistema de equivalencias considerando sus distintos consumos forrajeros, en este caso de ovinos: 1 ovino= 1 caprino/ 5 bovinos / 10 equinos (INTA, 2004).

${ }^{10}$ No es posible analizar la evolución entre 2014 y 2015 porque en 2015 se introdujeron nuevas madres tanto de Cabras Criollas Neuquinas como de ovinos en el marco de la continuidad de los proyectos de repoblamiento.
} 
TABLA 2 - Promedio del stock de madres, según especie- raza y año.

\begin{tabular}{lll}
\hline Especie- Raza/ Año & $\mathbf{2 0 1 5}$ & $\mathbf{2 0 1 6}$ \\
\hline Cabras Criollas Neuquinas & 34 & 39 \\
Cabras Angora & 57 & 60 \\
Ovejas Merino & 77 & 65 \\
\hline
\end{tabular}

FUENTE: Elaboración propia en base a Relevamiento 2017.

TABLA 3 - Índice de señalada, según especie- raza y año.

\begin{tabular}{lll}
\hline Especie- Raza/ Año & $\mathbf{2 0 1 5}$ & $\mathbf{2 0 1 6}$ \\
\hline Cabras Criollas Neuquinas & 0,98 & 0,93 \\
Cabras Angora & 0,85 & 0,72 \\
Ovejas Merino & 0,54 & 0,76 \\
\hline
\end{tabular}

FUENTE: Elaboración propia en base a Relevamiento 2017.

señalada de Cabras Criollas Neuquinas por proyecto. El proyecto de Ingeniero Jacobacci del 2014 fue el más exitoso en términos productivos (crecimientos anuales del stock de madres superiores al 20\%) y se relaciona con el ingreso en la mayoría de los predios de madres jóvenes y animales en buena condición corporal. En los otros dos proyectos (Comallo 2014 e Ingeniero Jacobacci 2015), debido a demora en la asignación de los fondos, las cabras que se consiguieron para el repoblamiento fueron de edad más avanzada, se trasladaron en plena época invernal y algunas ya preñadas. Esto generó sufrimiento en los animales afectando su preñez y condición corporal. Especialmente sucedió en Ingeniero Jacobacci 2015, donde se combinó temporalmente con nevadas intensas durante la llegada de los animales, que cubrieron durante semanas el suelo e imposibilitaron el pastoreo (Villagra et al., 2016) y los problemas con el transporte anteriormente mencionados. Si bien estas diferencias observadas por el momento de introducción y las condiciones de los animales van desapareciendo luego del tercer año de su ingreso, su consideración resulta importante en futuras políticas de repoblamiento porque condicionan sus resultados.

En cuanto al manejo, la evaluación no evidenció dificultades, pese a los prejuicios y temores

TABLA 4 - Evolución del stock de madres de Cabras Criollas Neuquinas por proyecto y año.

\begin{tabular}{llll}
\hline Proyecto/ Año & $\mathbf{2 0 1 4}$ & $\mathbf{2 0 1 5}$ & $\mathbf{2 0 1 6}$ \\
\hline Ingeniero Jacobacci 2014 & 29 & 42 & 54 \\
Comallo 2014 & 29 & 30 & 31 \\
Ingeniero Jacobacci 2015 & & 29 & 25 \\
\hline
\end{tabular}

FUENTE: Elaboración propia en base a Relevamiento 2017.

TABLA 5 - Evolución del índice de señalada de Cabras Criollas Neuquinas por proyecto y año.

\begin{tabular}{llll}
\hline Proyecto/ Año & $\mathbf{2 0 1 4}$ & $\mathbf{2 0 1 5}$ & $\mathbf{2 0 1 6}$ \\
\hline Ingeniero Jacobacci 2014 & 1,27 & 1,16 & 0,95 \\
Comallo 2014 & 0,65 & 1,04 & 1,03 \\
Ingeniero Jacobacci 2015 & & 0,65 & 0,77 \\
\hline
\end{tabular}

FUENTE: Elaboración propia en base a Relevamiento 2017.

previos que tenían algunos productores y técnicos respecto a la incorporación de las Cabras Criollas Neuquinas -en relación a su mayor capacidad de desplazamiento que podría haber dificultado el manejo y producir el servicio inoportuno. Tampoco se registraron pérdidas significativas o servicios no controlados. Solamente siete productores indicaron haber adelantado la fecha del servicio o haber hecho un servicio por separado, por las necesidades de mano de obra familiar que implicaban esas tareas. En contraposición, destacaron la habilidad materna, la facilidad en su manejo, menor selectividad para la alimentación, la buena producción de carne y la prolificidad de las Cabras Criollas Neuquinas. De esta manera, la cantidad asignada de animales a través de los proyectos permitió una familiarización paulatina, sin que sea disruptiva con sus prácticas 
de manejo previas. Inclusive algunos productores pudieron realizar sus propias pruebas para conocer cómo podían mejorar la productividad o solucionar problemas, como la utilización de los machos criollos para el servicio de Cabras Angora. Este tipo de prácticas son centrales para lograr una apropiación y la difusión en la zona del recurso genético reintroducido, derribando prejuicios y temores.

La reintroducción de Cabras Criollas Neuquinas contribuyó, además, a incrementar la diversificación ganadera de los pequeños productores: 97\% las combinaba con algún otro recurso animal, principalmente con Ovejas Merino y Cabras Angora (Tabla 6). A diferencia del modelo habitual de la Patagonia (el monocultivo ovino para la exportación de lanas), estos esquemas productivos diversificados resultan menos vulnerables frente a los eventos climáticos extremos.
Otro objetivo planteado con la iniciativa del repoblamiento ganadero era la contribución a la seguridad alimentaria. El 81\% de los productores manifestaron haber aprovechado las cabras para la provisión de carne, lo cual resulta muy importante para este sector de productores, según de Obschatko et al. (2007). A dos o tres años de la implementación de los primeros proyectos, el $78 \%$ de los productores y sus hogares llegaron a cubrir sus propias necesidades de consumo de carne a partir de los rumiantes menores. Además, la provisión de carne de Cabras Criollas Neuquinas ha permitido disminuir la faena de los animales de esquila, facilitando el incremento del stock animal, de lana y pelo disponible para la venta.

Respecto a la comercialización de las Cabras Criollas Neuquinas, el $61 \%$ de los productores declararon haber tenido ingresos monetarios, prin-

TABLA 6 - Cantidad y combinación de especies/razas por unidades domésticas (en porcentaje).

\begin{tabular}{lll}
\hline Cantidad de especies & Combinación de especies/razas & Unidades domésticas en \% \\
\hline 1 especie & CCN & 3 \\
\hline 2 especies & CCN-A & 7 \\
\hline \multirow{3}{*}{3 especies } & CCN-A-M & 26 \\
\cline { 2 - 3 } & CCN-M-E & 9 \\
\cline { 2 - 3 } & CCN-A-E & 12 \\
\cline { 2 - 3 } 4 especies & CCN-E-B & 23 \\
\hline 5 especies & CCN-A-M-E & 1 \\
\cline { 2 - 3 } Total & CCN-M-E-B & 1 \\
\hline
\end{tabular}

LEYENDA: CCN: Cabra Criolla Neuquina; A: Cabras Angoras; M: Ovejas Merino; E: Equino; B: Bovino.

FUENTE: Elaboración propia en base a Relevamiento 2017. 
cipalmente a través de la venta de "chivitos" algunos casos de pelo. Como comentó una productora, "A veces no tenemos plata, no tenemos sueldo, no tenemos nada y vendemos chivo y podemos sacar unos pesos" (Productora, Comallo, Taller, julio de 2017). En el relevamiento 2017, se registraron datos sobre las ventas del año anterior de 20 productores. En promedio, vendieron 21 animales cada uno. Los ingresos que generan estas ventas eran equivalentes a la compra general de alimentos e insumos que realizan los productores antes del invierno y que les dura prácticamente todo el año, según datos relevados por la Federación de Cooperativas de la Región Sur. Las ventas se hicieron tanto de forma individual como colectiva. Esta última fue novedosa en la región, ya que la concentración de la producción hacia la obtención de fibras no ha fomentado el desarrollo de un comercio de carne. Se elaboró también a partir del trabajo conjunto entre las organizaciones de productores y los organismos participantes de la iniciativa y nuevas organizaciones sociales, como el matadero frigorífico de Ingeniero Jacobacci y el Mercado Comunitario de Bariloche ${ }^{12}$. Estas estrategias constituyen nuevas formas de establecer o reforzar vínculos directos (cadenas cortas) entre productores y consumidores, que contribuyen al impacto socio-económico local y regional de la iniciativa, canalizando excedentes al mercado.

Si bien aún no se realizó una evaluación de las transformaciones socioeconómicas motivadas por la iniciativa, se registraron indicios de algunos aportes que permitieron la compra de bienes (principalmente vehículos), mejoras de infraestructura de los hogares y construcción de obras prediales, contribuciones para facilitar el acceso a la educación y la mejora en la calidad de vida de los hogares (Técnicos, entrevistas, Ingeniero Jacobacci y Comallo, mayo de 2018). "Yo tengo mi señora y cinco chicos. Tengo una de las nenas estudiando en Bariloche. Fue una bendición de Dios, poder vender algunos chivitos y tener plata para lo que necesiten, de comprar lo que necesiten, poder pagarle el alquiler" (Productor, Comallo, Taller, julio de 2017).

La valoración de la iniciativa de repoblamiento por parte de la mayoría de los participantes también es positiva ya que, frente a la pérdida que habían sufrido, los animales les permitieron recuperar su modo de garantizar la subsistencia familiar: "lo que aqui hizo posible que los productores pudieran seguir en el campo, fueron las chivas criollas" (Representante del Municipio, Comallo, Taller, julio de 2017) "Agradecidos porque nos da esperanza [refiriéndose a la incorporación de las cabras]... es lo que nos va a dar la vida, ¿no? " (Productora, Comallo, Taller, julio de 2017). Según el relevamiento, $73 \%$ de los encuestados manifestaron interés por incrementar la cantidad de Cabras Criollas Neuquinas en sus predios, siendo entre los 50 y 250 animales el número deseado porque les permitiría seguir manteniendo la diversidad de especies. La estimación se basa en un balance hecho por los mismos productores respecto a la superficie, los recursos naturales (principalmente forraje), la fuerza de trabajo y la diversidad de especies que poseen.

La devolución de los créditos constituye otro indicador que posibilita visualizar los resultados y la

\footnotetext{
11 "Chiva" o "chivita" es la denominación de la Cabras Criollas Neuquinas utilizada por los productores de la zona.

${ }^{12}$ En el taller los productores destacaron este espacio (distante a $120 \mathrm{~km}$ de Comallo y $218 \mathrm{~km}$ de Ingeniero Jacobacci) porque obtuvieron un mayor margen de precios y el pago fue inmediato.
} 
consolidación de la iniciativa. Habiéndose cumplido el período de gracia, los primeros beneficiarios ya comenzaron la devolución. Como se observaba en la tabla 2, en 2018, en el área de Ingeniero Jacobacci, se juntaron 540 cabras, correspondientes a 30 de los 34 productores participantes (casi 90\%). Éstas permitieron conformar lotes para entregar a 18 nuevos productores de zonas antes no contempladas y en asociación a otras organizaciones. Asimismo, las organizaciones que participaron de esas primeras experiencias pudieron rendir la totalidad de los recursos asignados.

En los últimos dos años, la iniciativa mantuvo su continuidad a través de dos mecanismos. En primer lugar, se siguieron incorporando nuevos productores al repoblamiento ganadero, gracias a la mencionada devolución de los animales y a la presentación de nuevos proyectos para ampliar el alcance territorial. Las organizaciones se han convertido en referentes de la iniciativa y receptores de las demandas por parte de productores para incorporarse a futuros proyectos.

En segundo lugar, motivado por los resultados de la instancia de evaluación, se han desarrollado nuevas líneas de trabajo en el territorio, con el objetivo de lograr un mejor aprovechamiento de las cabras, a partir de la diversificación de los productos obtenidos. Dada la historia productiva local, se comenzó con la colecta de fibra de cashmere. Nuevamente, esta estrategia de intervención está basada en el conocimiento local generado en el norte neuquino (Lanari et al., 2017), pero desde este proyecto se contempló que su difusión no sea sólo desde los técnicos o profesionales, sino a partir de los mismos productores. Quienes participaron en el taller compartieron experiencias prácticas sobre la técnica del peinado para la extracción de cashmere
(Figura 4). Además, se realizaron capacitaciones sobre obtención de cueros y elaboración de quesos. Esto último fue posible por la cantidad de leche que producen las Cabras Criollas Neuquinas, y no lo sería con otras razas de cabras y los ovinos.

\section{Conclusiones}

La iniciativa de repoblamiento con Cabras Criollas Neuquinas se diseñó en un contexto crítico, posterior a un desastre natural, en un área cuyo poblamiento, economía y dinámica social estuvo históricamente centrada en la ganadería extensiva para la producción de fibras. La recomposición del stock ganadero y con ello, de la economía predial resultaba central por su relación con el éxodo rural. La iniciativa de repoblamiento analizada fue ideada con un enfoque diferente, cuestionando el modelo productivo vigente basado en la exportación de fibras finas, para adoptar una raza local que tenía mejores aptitudes para adaptarse a las condiciones naturales y podía contribuir a la seguridad alimentaria y a generar excedentes para la venta en el mercado local.

La iniciativa contó con un diseño que se basó en la preexistencia de vínculos formales e informales entre técnicos e investigadores de distintos organismos del Estado que trabajaban en la zona. Se podría hablar de la conformación de una red social e interinstitucional, basada en el aprovechamiento de recursos genéticos, conocimientos y saberes locales, que permitieron no sólo satisfacer las demandas iniciales sino también promover nuevas estrategias de producción que fomentan la diversificación de los ingresos, reducen la vulnerabilidad socioeconómica 


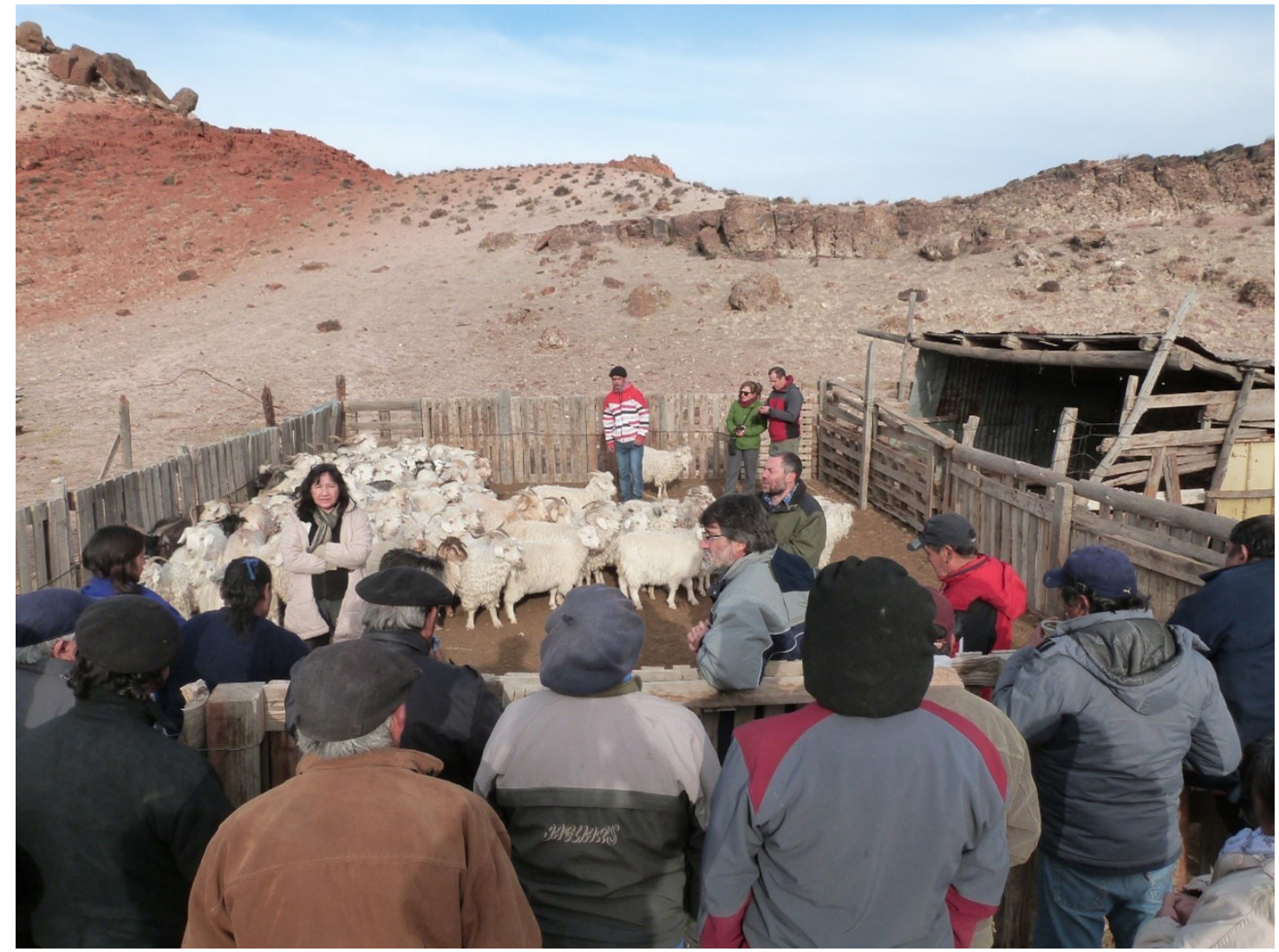

FIGURA 4 - Taller de peinado de cabras Cabras Criollas Neuquinas (Comallo, Río Negro, Patagonia Argentina- 2017).

FUENTE: Imagen tomada en Comallo, Río Negro (2017).

y promueven una mejor adaptación y capacidad de resiliencia frente a posibles desastres naturales.

Si bien en el origen de la propuesta los productores fueron principalmente receptores de la misma, en la implementación su participación resultó central, ya que intervinieron en la selección de los beneficiarios, consolidando saberes y experimentando las formas de manejo de las cabras, reforzando prácticas históricas e incorporando nuevas. A su vez, promovieron nuevos objetivos y demandas hacia los organismos técnicos. En efecto, estuvo lejos de aquellas visiones pragmáticas sobre lo ambiental que promueven la resolución de problemas basados en modelos científicos sin considerar otros saberes o los cuestionamientos sociales.

Esta política pública tampoco hubiera funcionado sin la existencia de productores organizados y el apoyo de los gobiernos locales que permitieron alcanzar los objetivos por su proximidad y capacidad de gestión. Especialmente, la conformación de una red de trabajo en las instancias de implementación y evaluación permitió una mayor eficiencia en el 
desarrollo de la iniciativa y facilitó la reorientación de las actividades. Su involucramiento en las distintas fases contribuyó a consolidarse como organizaciones sociales, tejer nuevos vínculos e inclusive ampliar sus objetivos y base social, convirtiéndose en referentes para sus comunidades.

En síntesis, la iniciativa de repoblamiento con Cabras Criollas Neuquinas es un claro ejemplo de una política pública construida y sostenida en y desde el territorio. Su diseño sencillo, con un mecanismo de devolución y contrapartes acordes a las posibilidades de los beneficiarios, y adaptado a las necesidades y saberes locales, permitió alcanzar los objetivos iniciales y extender su alcance con nuevos propósitos y líneas de acción.

El caso analizado muestra cómo una política pública ambiental puede combinar metas de corto plazo, de combate a la emergencia, con metas de largo plazo a partir de la identificación de nuevas oportunidades surgidas en la implementación, el trabajo participativo y un proceso de evaluación continuo y sostenido en el tiempo. La consecución de nuevos objetivos (por ejemplo, el desarrollo de circuitos cortos de comercialización de nuevos productos derivados de las cabras) requiere de articulaciones con otras organizaciones sociales (de artesanas y consumidores, entre otros), pero ahora en zonas urbanas. Ello plantea el desafío de una visión del territorio de modo relacional, que vincule actores sociales en condiciones de vulnerabilidad tanto en "lo rural" como en "lo urbano".

Esta iniciativa parte de la posibilidad de contemplar que las políticas de repoblamiento frente a desastres naturales sean realizadas con los recursos presentes en el área y/o con capacidad comprobada de adaptación a las condiciones de la zona. Asimismo, es posible que ese tipo de animales hayan sido conservados porque contribuyen en distintos sentidos a la reproducción social y la economía de los productores. En el caso analizado, las $\mathrm{Ca}-$ bras Criollas Neuquinas han resultado un recurso mixto, permitiendo obtener tanto carne para su autoconsumo como ingresos monetarios. También han contribuido a diversificar las especies animales en cada predio, reduciendo la vulnerabilidad frente a otros eventos climáticos adversos y generando nuevas fuentes de ingresos.

Asimismo, la prolificidad de los animales a utilizar en un repoblamiento resulta clave porque reduce el tiempo necesario para garantizar el sustento y la cantidad que deben ser entregados en un primer momento por su rápida reproducción.

Por último, resulta importante tener en cuenta algunas cuestiones centrales en el momento de la implementación, cuyo descuido puede atentar contra la eficacia de una política, inclusive en aquellas que presentan un sólido diseño. A partir del caso estudiado, se plantea como central identificar la fecha óptima para la compra y traslado de los animales (en la Línea sur sería entre marzo y abril, cuando se produce el retorno de los campos de veranada y antes del servicio en el mes de mayo, cuando el clima aún es favorable); utilizar animales jóvenes que permitan su reproducción rápidamente en el lugar de destino; y contar con la intervención de mediadores sociales, que logren activar el compromiso y la confianza entre los participantes y puedan contribuir a resolver eventuales problemas que sucedan en el territorio. 


\section{Agradecimientos}

Esta experiencia no hubiera sido posible sin la participación de todos los productores y los integrantes de las organizaciones y las instituciones públicas mencionadas, especialmente Alejandro Fornasa, Ana María Cumilaf, Iván Centelles, Alejandro Mogni y Luciano Mammoni. Reconocemos también el trabajo de Martín Moronta, Gustavo Apablaza y Abigaelle Mauger en el relevamiento y procesamiento inicial de los datos. Agradecemos a los dos evaluadores anónimos por su lectura y aportes para el artículo.

\section{Referencias}

Alimonda, H. Paisajes del Volcán de Agua (aproximación a la Ecología Política Latinoamericana). In: Alimonda, H.; Parreira, C. (Eds.) Politicas públicas ambientais latino-americanas. Brasilia: FLACSO Brasil/Abaré, p. 65-80, 2005.

Álvarez Sánchez, A.; Ejarque, M. Respuestas públicas y problemas ambientales: las políticas para la actividad lanera frente a la deposición de cenizas del volcán Puyehue en Chubut y Río Negro. In: VII Jornadas de Sociología de la UNLP. La Plata, dic. 2012.

Andrade, L. Sociología de la desertificación: los productores ovino extensivos de la Patagonia austral. Buenos Aires: Miño y Dávila, 2005.

Arasio, R. Rebuilding Herds by Reinforcing Gargar/Irb Among the Somali Pastoralists of Kenya. OFDA/USAID, 2004. Disponible en: <http://sites.tufts.edu/capeipst/files/2011/03/Lotira-Restocking-evaluation.pdf $>$. Acceso: jul. 2018.

Argentina. Ley $N^{o} 26.509$, del 20 de agosto. Créase el Sistema Nacional para la Prevención y Mitigación de Emergencias y Desastres Agropecuarios. Buenos Aires: BO del 28/08/2005.

Argentina. Ley $N^{\circ} 26.141$, del 18 de septiembre. Ley para la recuperación, fomento y desarrollo de la actividad caprina. Buenos Aires: BO del 21/09/2006.

Argentina. Ley $N^{\circ} 26.680$, del 4 de mayo. Prorrógase la vigencia de la obligación contemplada en la Ley n. 25422 para la recuperación de la ganadería ovina. Buenos Aires: BO del 31/05/2011a

Argentina. Ley $N^{o} 26.698$, del 3 de agosto. Programa transitorio de retención y reposición de vientres ovinos y caprinos para pequeños y medianos productores. Condonación de capital e intereses de créditos otorgados a productores afectados por la sequía y cenizas volcánicas en el marco de la Ley 25.422, régimen para la recuperación de la ganadería ovina. Buenos Aires: BO del 24/08/2011b.

Argueta Villamar, A.; Pérez Ruiz, M. L. Los saberes tradicionales y los desafíos para el diálogo de conocimientos. Desenvolvimento e meio ambiente, 50, 49-72, 2019. doi: doi.org/10.5380/dma.v50i0.65438

Azuela, A. Visionarios y pragmáticos: una aproximación sociológica al derecho ambiental. México: UNAM- Instituto de Investigaciones Sociales; Fontanamara, 2006.

Bandieri, S. Historia de la Patagonia. Buenos Aires: Sudamericana, 2009.

Bendini, M.; Steimbreger, N. Dinámicas territoriales y persistencia campesina: redefinición de unidades y espacios de trabajo de los crianceros en el norte de la Patagonia. Transporte y Territorio, 3, 59-76, 2010. doi: $10.34096 \% 2$ Frtt. i3.246

Blaikie, P.; Cannon, T.; Davis, I.; Wisner, B. At Risk: natural hazards, people's vulnerability and disasters. Londres: Routledge, 1994.

Bowen, G. Document Analysis as a Qualitative Research Method. Qualitative Research Journal, 9, 2, 27-40, 2009. doi: 10.3316/QRJ0902027

Bran, D.; Velasco, V.; Gaitán, J. Sitio Piloto en la Región Patagonia Norte. In: Ravelo, A.; Planchuelo, A.; Abraham, E.; Navone, S. (Eds.) Evaluación de la desertificación en Argentina. Buenos Aires: FAO, p. 243-293, 2011.

Caballeros Otero, R.; Zapata Martí, R. The Impacts of Natural Disasters on Developing Economies: Implications for the International Development and Disaster Community. 
World Conference on Natural Disaster Reduction. Japan: World Bank y US National Academy of Sciences, 1994. Disponible en: $<$ http://cidbimena.desastres.hn/docum/crid/ Jun-Jul2004/pdf/eng/doc4907/doc4907.htm>. Acceso en: jul. 2018.

Carballo, C. Soberanía alimentaria y producción de alimentos en Argentina. In: de Gorban, M.; Carballo, C.; Paiva, M.; Abajo, V.; Filardi, M.; Giai, M.; Veronese, G. Graciano, A.; Risso Patrón, V.; Broccoli, A.; Gilardi, R. Seguridady Soberanía Alimentaria. Buenos Aires: Colección Cuadernos, p. 11-48, 2011.

Cowan Ros, C.; Nussbaumer, B. Trayectoria conceptual de la mediación social: expedicionarios, patrones, políticos y profesionales técnicos en la interconexión y producción de mundos de significado. In: Nussbaumer, B.; Cowan Ros, C. (Eds). Mediadores sociales: en la producción de prácticas y sentidos de la política pública. Buenos Aires: Fundación Ciccus, p. 17-68, 2011.

De Gorban, M.; Carballo, C.; Paiva, M.; Abajo, V.; Filardi, M.; Giai, M.; Veronese, G.; Graciano, A.; Risso Patrón, V.; Broccoli, A.; Gilardi, R. Seguridady Soberanía Alimentaria. Buenos Aires: Colección Cuadernos, 2011.

de Obschatko, E.; Foti, M.P.; Román, M. Los pequeños productores en la República Argentina: importancia en la producción agropecuaria y en el empleo en base al censo nacional agropecuario 2002. Buenos Aires: Secretaría Agricultura, Ganadería, Pesca y Alimentos e Instituto Interamericano de Cooperación para la Agricultura, 2007.

Descola, P.; Pálsson, G. Nature and society. London: Routledge, 2001.

Easdale, M.; Villagra, S.; Bidinost, F.; Peralta, C. Estado de situación y propuesta de acción para la producción ganadera afectada por la sequía y la ceniza volcánica en la Provincia de Río Negro. Bariloche: INTA EEA Bariloche, 2011. Disponible en: < http://sipan.inta.gov.ar/contenido/ bibliografia/pdf/21.PDF>. Acceso en: jul. 2018.

Ejarque, M. La construcción social de los problemas ambientales en torno a la ganadería ovina de las tierras secas chubutenses: agentes sociales, sus interpretaciones y sus prácticas. Buenos Aires, Tesis (Doctorado en Ciencias Sociales) - Universidad de Buenos Aires, 2015.
FAO - Food and Agriculture Organization. The State of the World's Animal Genetic Resources for Food and Agriculture. Rome: Food and Agriculture Organization of the United Nations, 2007. Disponible en: <http://www.fao. org/3/a1250e/a1250e.pdf $>$. Acceso en: jul. 2018.

FAO - Food and Agriculture Organization. Coping with climate change - the roles of genetic resources for food and agriculture. Rome: Food and Agriculture Organization of the United Nations, 2015. Disponible en: <http://www.fao. org/3/a-i3866e.pdf>. Acceso en jul. 2018.

Floriani, D.; Vergara N. Hacia un pensamiento socioambiental: aproximaciones epistemológicas y sociológicas. Desenvolvimento e meio ambiente, 35, 11-27, 2015. doi: 10.5380/dma.v35i0.43541

Gaitán, J.; Raffo, F.; Ayesa, J.; Umaña, F.; Bran, D. Cartografía del área afectada por cenizas volcánicas en las provincias de Río Negro y Neuquén. Bariloche: Laboratorio de Teledetección - SIG, Estación Experimental S.C. de Bariloche, Instituto Nacional de Tecnología Agropecuaria (INTA), 2011. Disponible en: <https://inta.gob.ar/sites/ default/files/script-tmp-cartografa_cenizas.pdf $>$. Acceso en: jul. 2018.

Galafassi, G. Capital, naturaleza y territorio en Patagonia. Rediscutiendo las tesis sobre la acumulación primitiva. A contracorriente, 8, (1), 198-229, 2010. Disponible en: https://acontracorriente.chass.ncsu.edu/index.php/acontracorriente/article/view/488

Ghermandi, L.; Gonzalez, S. Observaciones tempranas de la deposición de ceniza por la erupción volcánica del Cordón Caulle y sus consecuencias sobre la vegetación de la estepa del NO de la Patagonia. Ecología Austral, 22, 2, 144-49, 2012. Disponible en: http://hdl.handle.net/11336/73515

Giarracca, N.; Teubal, M. Actividades extractivas en expansión. ¿Reprimarización de la economía argentina? Buenos Aires: Antropofagia, 2013.

Göbel, B.; Góngora Mera, M.; Ulloa, A. Desigualdades socioambientales en América Latina. Biblioteca Abierta, Perspectivas ambientales. Bogotá: Universidad Nacional de Colombia- Ibero-Amerikanisches Institut, 2014.

Granovetter, M. The strength of weak ties: a network theory revisited. Sociological Theory, 1, 201-33, 1983. 
Gura, S. Livestock Genetics Companies. Concentration and proprietary strategies of an emerging power in the global food economy. Ober-Ramstadt, Germany: League for Pastoral Peoples and Endogenous Livestock Development, 2007. Disponible en: <http://www.fao.org/tempref/GI/Reserved/ FTP_FaoRlc/old/prior/segalim/animal/pdf/Livege.pdf $>$. Acceso en: jul. 2018.

Heffernan, C.; Misturelli, F.; Nielsen, L. Restocking and poverty alleviation: Perceptions and realities of livestock keeping among poor pastoralists in Kenya. Report for DFID's Livestock Production Programme, NRI, Greenwich, 2001. Disponible en: <https://assets.publishing.service. gov.uk/media/57a08d2440f0b64974001690/R7402a.pdf>. Acceso en: jul. 2018.

Heffernan, C.;Rushton, J. Restocking: A Critical Evaluation. Nomadic Peoples, 4, 1,110-124, 2001.

INTA- Instituto Nacional de Tecnología Agropecuaria. Sistema de Soporte de Decisiones. Bariloche: INTA EEA Bariloche, 2004.

Irisarri, G.; Oesterheld, M.; Paruelo, J.; Baldassini, P.; Arocena, D.; Oyarzabal, M. Impacto de la erupción del volcán Puyehue y el déficit de precipitaciones sobre la producción de materia seca del Suroeste de Río Negro. Buenos Aires: LART -Laboratorio de Análisis Regional y Teledetección, IFEVA-FAUBA-CONICET, 2012. Disponible en: $<$ http:// www.agro.uba.ar/laboratorios/lart>. Acceso en: jul. 2018.

Jamshed S. Qualitative research method-interviewing and observation. Journal of basic and clinical pharmacy, 5(4), 87-88, 2014. doi: 10.4103/0976-0105.141942

Lahera, E. P. Política y políticas públicas. Santiago de Chile: Naciones Unidas, 2004.

Lampis, A. Vulnerabilidad y adaptación al cambio climático: debates acerca del concepto de vulnerabilidad y su medición. Cuadernos de Geografía, 2, 22, 17-33, 2013. doi: $10.15446 /$ rcdg

Lanari, M. R. Variación y diferenciación genética y fenotípica de la Cabra Criolla Neuquina en relación con su sistema rural campesino. Bariloche, Tesis (Doctorado en Ciencias Biológicas) - Facultad de Biología, Centro Regional Universitario Bariloche, Universidad Nacional del Comahue, 2004.
Lanari, M. R.; Losardo, P.; Fornasa, A.; Pérez Centeno, M. Lecciones de un premio. Presencia, 67, 39-42, 2017.

Lanari, M. R.; Maurino, J.; Giovannini, N. Productividad de la Cabra Criolla Neuquina durante la erupción del Volcán Puyehue. In: $35^{\circ}$ Congreso de la Asociación Argentina de Producción Animal. Córdoba, oct. 2012.

Landini, F. La dinámica de los saberes locales y el proceso de localización del saber científico. Algunos aportes desde un estudio de caso. Cuadernos de Desarrollo Rural, 7, 65, 21-43, 2010. Disponible en: https://revistas.javeriana.edu. co/index.php/desarrolloRural/article/view/1159

Lattuada, M.; Nogueira, M. E.; Urcola, M. Tres décadas de desarrollo rural en la Argentina. Buenos Aires: TeseoUniversidad Abierta Interamericana, 2015.

Louwrens, A. Livestock restocking as a possibility for sustained production with specific reference to the Namibian situation. Agricola, 90-93, 2001. Disponible en: http://www. nbri.org.na/sites/default/files/Agricola2001_No12_18_Louwrens.PDF

LPP - League for Pastoral Peoples; LIFE Network; IUCNWISP - International Union for Conservation of NatureWorld Initiative for Sustainable Pastoralism; FAO - Food and Agriculture Organization. Adding value to livestock diversity - Marketing to promote local breeds and improve livelihoods. Roma: FAO Animal Production and Health Paper, 2010. Disponible en: <http://www.fao.org/3/i1283e/ i1283e.pdf>. Acceso en: jul. 2018.

MacDonald, A.; Main, B.; Namarika, R.; Yiannakis, M.; Mildon, A. Small-animal revolving funds: an innovative programming model to increase access to and consumption of animal-source foods by rural households in Malawi. In: Thompson, B.; Amoroso, L. (Eds.) Combating Micronutrient Deficiencies: Food-based Approaches. Londres: FAO- CABI, 2011.

March, J. A. Integrating Natural Resource Management into Disaster Response and Mitigation. Integrating Ecology and Poverty Reduction, 393-406, 2011. doi: 10.1007/9781-4419-0633-5_23

Martínez, R. Prejuicios que afectan a bovinos y ovinos criollos en Argentina. Actas Iberoamericanas de Conservación Animal, 5, 26-35, 2015. 
Moldes, B.; Entraigas, J.; Heredia, N.; Schenfelt, A. Travesías, caminos y jagüeles. Las bases iniciales para el poblamiento en las áreas de bajos y salitrales ubicados en las mesetas del curso medio del río Negro (1885-1930). In: Masera, R.; Guarido, J. (Eds.) Bajo del Gualicho: Una Planicie patagónica bajo el nivel del mar, Viedma: Secretaría de Estado Acción Social de Rio Negro, p. 59-122, 2003.

Muzi, M. E.; Losardo. P. Caracterización socio-productiva de la situación postceniza del área de Comallo (Río Negro). Revista de investigaciones agropecuarias, 41 (3), 263-69, 2015.

O’Donnell, G. Acerca del Estado en América Latina. Diez tesis para discusión. In: Programa de las Naciones Unidas para el Desarrollo (Ed.) La democracia en América Latina: hacia una democracia de ciudadanas y ciudadanos. Buenos Aires: Aguilar, p. 149-92, 2004.

Ojala, R.; Mugisha, A.; Ocaido, M. Factors affecting livestock restocking projects in Southern Teso of Eastern Uganda. Africa Journal of Animal and Biomedical Sciences, 5, 2, 99-105, 2010.

Oszlak, O. Estado, planificación y burocracia: los “procesos de implementación" de las políticas públicas en algunas experiencias latinoamericanas. In: Instituto Nacional de Administración Pública (Ed.) 25 aniversario del INAP 1955-1980. México: INAP, p. 205-231, 1980. Disponible en: http://oscaroszlak.org.ar/images/articulos-espanol/Estado, $\% 20$ planificacion $\% 20 \mathrm{y} \% 20$ burocracia.pdf

Oszlak, O. Implementación participativa de políticas públicas: aportes a la construcción de un marco analítico. In: Belmonte, A. (Ed.). Construyendo confianza: hacia un vínculo entre estado y sociedad civil. Buenos Aires: CIPPEC y Subsecretaría para la Reforma Institucional y Fortalecimiento de la Democracia, Jefatura de Gabinete de Ministros, Presidencia de la Nación, p. 9-47, 2009. Disponible en: https://www.cippec.org/wp-content/uploads/2017/03/1753.pdf

Pérez Centeno, M. Transformations des stratégies sociales et productives des éleveurs transhumants de la province de Neuquén et de leurs relations avec les interventions de développement. Toulouse, Tesis (Doctorat Etudes RuralesMention Développement Rural) - Université Toulouse Le Mirail, 2007.
Río Negro. Decreto Provincial $n^{\circ} 497$, del 8 de junio. Declárase el estado de emergencia agropecuaria en la Provincia de Río Negro, a los efectos de la Ley n. 26509. Viedma: B.O del 16/6/11.

Schweitzer, A. F. Patagonia, naturaleza y territorios. Geograficando, 10, 2, 1-24, 2014. Disponible en: http://www.geograficando.fahce.unlp.edu.ar/article/view/Geov10n02a11

Scoones, I. New Ecology and the Social Sciences: What Prospects for a Fruitful Engagement? Annual Review of Anthropology, 28, 479-507, 1999.

Sinnott, E.; Nash, J.; de la Torre, A. Natural resources in Latin America and the Caribbean: beyond booms and busts? Washington, DC: World Bank, 2010.

Steimbreger, N.; Kreiter, A. Dinámicas rurales. Una mirada acerca de la situación actual de los Pueblos en la Patagonia. Huellas, 14, 31-52, 2010. Disponible en: http://www. biblioteca.unlpam.edu.ar/pubpdf/huellas/n14a03kreiter.pdf

Tamayo Sáez, M. Capítulo 11: El análisis de las políticas públicas. In: Bañón, R.; Carrillo, E. La nueva Administración Pública. Madrid: Alianza Universidad, 1997.

Tobías, M. Política del agua, controversias socio-técnicas y conflictos territoriales en el Área Metropolitana de Buenos Aires (2006-2015). Buenos Aires, Tesis (Doctorado en Ciencias Sociales y Geografía) - Universidad de Buenos Aires - Université Paris 3 Sorbonne Nouvelle, 2017.

Toledo, V. F. Hacia una conceptualización de las políticas públicas. Cuadernos Universitarios. Publicaciones Académicas de la Universidad Católica de Salta, 8, 63-71, 2015. Disponible en: https://www.ucasal.edu.ar/contenido/2016/ cuadernos-universitarios/pdf/sumario-cuadernoN8/Articulo6-politicas\%20publicas-Toledo.pdf

Villagra, S.; Ayesa, J.; Raffo, F.; Easdale, M. Análisis productivo y espacial de la zona afectada por la caída de cenizas del Cordón Caulle-Puyehue para la Patagonia Norte. Presencia, 57, 29-32, 2011.

Villagra, S.; Ayesa, J.; Umaña, F.; Deluchi, S.; Ocariz, P.; Subiabre, M.; Bidinost, F.; Velasco, V.; Maldonado, M.; Álvarez, R. Informe del estado de situación de la región afectada por nevadas en la Región Sur de la Provincia de Río Negro. Bariloche: INTA, EEA Bariloche, 2016. 
Disponible en: inta.gob.ar/sites/default/files/informe_ne- Wilson, T.; Stewart, C.; Bickerton, H.; Baxter, P.; Outes, vadas_en_rio_negro_290716_corregido.pdf Acceso en: V.; Villarosa, G.; Rovere, E. Impacts of the June 2011 Puyago. 2018 . ehue- Cordon Caulle volcanic complex eruption on urban infrastructure, agriculture and public Health. GNS Science Report 2012/20, 2013. Disponible en: <https://www.geonode-gfdrrlab.org/documents/763>. Acceso en: ago. 2018. 